\title{
Effects of fines content on hydraulic conductivity and morphology of laterite soil as hydraulic barrier
}

\author{
Yamusa Bello Yamusa ${ }^{1,2 *}$, Nor Zurairahetty Mohd Yunus ${ }^{1}$, Kamarudin Ahmad ${ }^{1}$, Norhan \\ Abd Rahman ${ }^{1}$, and Radzuan Sa'ari ${ }^{1}$ \\ ${ }^{1}$ Faculty of Civil Engineering, Universiti Teknologi Malaysia, 81310 Skudai, Johor, Malaysia \\ ${ }^{2}$ Department of Civil Engineering, Nuhu Bamalli Polytechnic, 810001 Zaria, Nigeria
}

\begin{abstract}
Laterite soil was investigated to find out the effects of fines content and to identify the micro-structural and molecular characteristics to evaluate its potentiality as a compacted soil landfill liner material. Tests were carried out on natural soil and reconstituted soil by dry weight of soil samples to determine the physical and engineering properties of the soil. All tests were carried out on the samples by adopting the British Standard 1377:1990. The possible mechanisms that contributed to the clay mineralogy were analyzed using spectroscopic and microscopic techniques such as field emission scanning electron microscopy (FESEM), energydispersive X-ray (EDX) and X-ray diffractometry (XRD). The laterite soil was found to contain kaolinite as the major clay minerals. A minimum of $50 \%$ fines content of laterite soil met the required result for hydraulic barriers in waste containment facilities.
\end{abstract}

\section{Introduction}

The vast increase in population associated with rapid development in industrial and agricultural production, more waste is being produced regularly. This waste is mostly disposed of in landfills. In order to minimize the environmental pollution caused by mankind, numerous scientific studies such as storing, transformation, and annihilation of wastes. But the most economical and the most confident is the impermeable nature of sanitary landfills, with respect to underground and surface waters for solid waste disposal [1]. Hydraulic barriers usually refer to liners and covers used for waste containment structures in engineered sanitary landfill design play the role in preventing/impeding fluid flow and attenuating inorganic contaminants. These hydraulics barrier's structural integrity must be ensured by adopting all the necessary and adequate criteria in their construction [2].

The minimum recommended criteria for sanitary landfill liners varies upon regulations set by different countries. The environmental protection agencies in developed countries, like the USA, UK, and most European countries recommended hydraulic conductivity $(\mathrm{k})$

* Corresponding author: yamusabello@yahoo.com 
of $\mathrm{k} \leq 1 \times 10^{-9} \mathrm{~m} / \mathrm{s}$ values for sanitary landfill liners [3]. The criteria set by most researches and regulatory agencies specified a hydraulic conductivity value of $\mathrm{k} \leq 1 \times 10^{-9} \mathrm{~m} / \mathrm{s}$, a volumetric shrinkage value of $\leq 4 \%$, and a value of $\geq 200 \mathrm{kN} / \mathrm{m}^{2}$ shear strength are required for hydraulic barrier systems [4-11]. This paper focused on the hydraulic conductivity criteria.

In constructing compacted soil liners for sanitary landfills, the most common materials used are fine-grained soils because of their relative economy and availability, and good engineering properties when compacted [12]. Though, the morphology, which relates to the structural pattern and mineral formation of soils are controlled by the fines particles. The reason FESEM, EDX and XRD were carried out to examine the minerology of the laterite soil. There is no information in published literature on the minimum percentage of fines required to be adopted in the design of compacted laterite soils as landfill liners and covers in waste containment applications [4]. Therefore, there is need to find the minimum gradation with respect to fines content that can satisfy the hydraulic conductivity criteria used in hydraulic barriers.

\section{Materials and methods}

\subsection{Natural Soil and Reconstituted Soil}

In this study, the natural laterite soil sample used was collected from the hilly area near the Faculty of Electrical Engineering at $1-1.5 \mathrm{~m}$ below the ground. Located on latitude $1^{\circ} 33^{\prime} 39^{\prime \prime N}$ and longitude 103 $38^{\prime} 44^{\prime \prime E}$, Skudai campus of Universiti Teknologi Malaysia (UTM).

The reconstitution of the laterite soil used in this study was air-dried and then passed through BS $4.75 \mathrm{~mm}$ aperture sieve to remove oversized gravel. The laterite soil was then sieved into three different grades i.e. fines $(<0.063 \mathrm{~mm})$, sand $(0.063 \mathrm{~mm}$ to $2.00 \mathrm{~mm})$ and gravel $(>2.00 \mathrm{~mm}$ to $\leq 4.75 \mathrm{~mm})$. The following gradation of laterite soil specimen were investigated:

Natural laterite soil sample with 30\% fines, $40 \%$ sand and $30 \%$ gravel.

For the reconstituted laterite soil;

(i) $40 \%$ fines, $40 \%$ sand and $20 \%$ gravel.

(ii) $50 \%$ fines, $40 \%$ sand and $10 \%$ gravel.

\subsection{Morphological and Mineralogical Composition}

Field emission scanning electron microscopy (FESEM) technique was used to examine the morphology and microstructural properties of the laterite soil fabric. Likewise, providing information on the size, shape, and the state of orientation and aggregation of soil particles [13]. This was used in conjunction with Energy Dispersive X-Ray Spectroscopy (EDX), which is a chemical microanalysis method to determine the elements present in the sample. The FESEM and EDX sample preparation is described as follows. Dry sample was prepared and placed on aluminum stub, and to prevent charging effect as well as loss of resolution it was then covered with carbon tape and coated with platinum using a vacuum sputter. Crossbeam 340 machine was used to analyze the sample connected to a computer as shown in Fig. 1. Moreover, X-ray diffraction (XRD) technique is primarily used to identify and characterize compounds based on their diffraction pattern. SmartLab X-ray diffractometer machine was used to analyze the sample connected to a computer as shown in Fig. 2. 


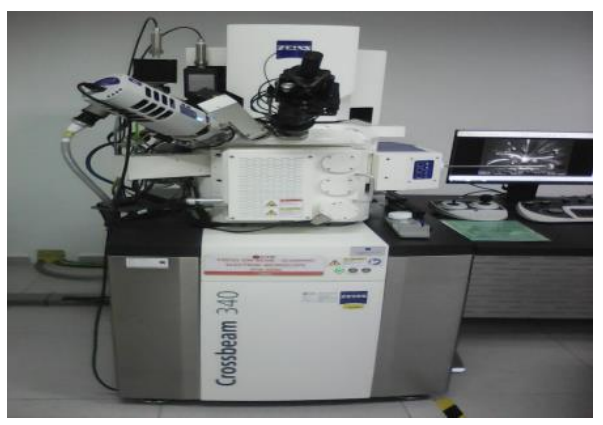

Fig. 1. Crossbeam 340 .

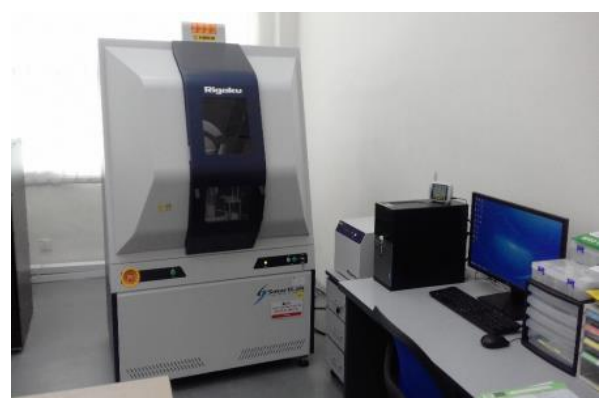

Fig. 2. SmartLab X-ray Diffractometer.

\subsection{Hydraulic Conductivity}

Rigid wall permeameter under falling head condition was used to measure the hydraulic conductivity as recommended by [14]. Soil samples were compacted using the BSL at $30 \%, 40 \%$ and $50 \%$ fines contents by varying the moulding water contents at $-4 \%,-2 \%$, $0 \%,+2 \%$ and $+4 \%$ of the optimum moisture content (OMC). Then the samples were soaked for a minimum period of 48 hours until no air bubbles are obviously observed to allow for full saturation inside a water tank. Then connected to distilled water through a standpipe. Readings of time and distance covered by distilled water in the standpipe were recorded and permeability $(\mathrm{k})$ calculated. Tests were repeated for different gradation at various moisture contents.

\section{Results and Discussion}

\subsection{Index properties}

British Standards (BS) [15] was followed in all the laboratory tests carried out to determine the index properties and particle size distribution of the soil as shown in Table 1 and Fig. 3 respectively. From the particle size distribution shown in Fig. 3, the natural laterite soil contains $30 \%$ fines, whereas the reconstituted laterite soils contain $40 \%$ fines and $50 \%$ fines. Furthermore, Atterberg limits results revealed a liquid limit of $76 \%$, plastic limit of $42 \%$, and plasticity index of $34 \%$. Based on these data, the laterite soil is classified according to the BS as sandy silt with gravel of very high plasticity (MV). Generally, low hydraulic conductivity is attained from soils with high liquid limit [16] recommended that 
the liquid limit of a liner material should be $\geq 20 \%$. Though, clay soils with too high liquid limit (LL) are more susceptible to desiccation cracking [12].

Table 1. Index properties of laterite soil.

\begin{tabular}{|c|c|}
\hline Property & Value \\
\hline Natural Moisture Content, $\%$ & 34 \\
\hline Specific Gravity & 2.7 \\
\hline$\%$ Passing BS $63 \mu \mathrm{m}$ sieve & 30 \\
\hline $\mathrm{OMC}, \%$ & 30 \\
\hline $\mathrm{MDD}, \mathrm{Mg} / \mathrm{m} 3$ & 1.35 \\
\hline Liquid Limit, \% & 76 \\
\hline Plastic Limit, \% & 42 \\
\hline Plasticity Index, $\%$ & 34 \\
\hline BS Classification & MV \\
\hline
\end{tabular}

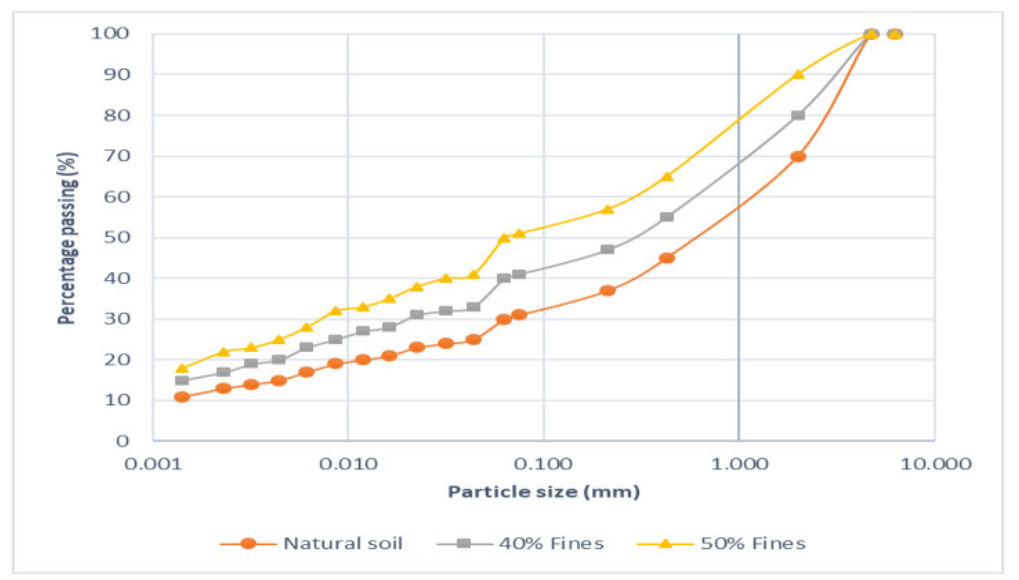

Fig. 3. Particle Size Distribution Curves.

\subsection{Morphological and Mineralogical Composition}

FESEM technique was used to examine the morphology and microstructural properties of the laterite soil fabric. From the FESEM micrograph shown in Fig. 4 (a \& b), there are presence of kaolinite flakes in the soil fabric. This was used in conjunction with EDX which is a chemical microanalysis method to determine the elements present in the sample. Moreover, EDX spectrum in Fig. 5 shows the present of element of oxygen, iron, aluminum, and silica. The oxide composition of the soil as given in Table 2 revealed the sample to be a laterite soil [17-19]. Laterite soil is whose ratio of iron oxide to aluminum oxide is less than 1.33 [20]. As shown in Fig. 4, the neatly arranged book-like kaolinite particles with free oxides present in the soil, and Kaolinitic and Halloysitic Flakes are the 
major feature of the natural soil in agreement with [21] and [22] respectively. According to [23] the free iron oxides in soils usually have special electrochemical properties, relatively great surface energy, and a strong ability to adsorb, and hence provide structural cementation in the soil. When free iron oxides exist in soil, there is an increase in strength, and a corresponding decrease in swelling-shrinkage capacity. It was observed that the sesquioxide ratio is 1.14 with very high concentrations of $\mathrm{Fe}_{2} \mathrm{O}_{3}, \mathrm{Al}_{2} \mathrm{O}_{3}$ and $\mathrm{SiO}_{2}$ of $35.53 \%$, 31.1 and 25.46 respectively, while $\mathrm{CO}_{2}$ has relatively low concentrations of $7.91 \%$.

$\mathrm{X}$-ray diffraction (XRD) technique is primarily used to identify and characterize compounds based on their diffraction pattern. As a popular fundamental investigation technique, XRD is easy to use and can give a wide range of instantly interpretable data on soil minerals $[13,19]$. The XRD quantitative analysis result and pattern that determined the clay mineralogy of the laterite soil was found to contain kaolinite as the major predominant mineral with some mixtures of gibbsite, goethite and cristobalite as presented in Table 3 and Fig. 6 respectively. According to [24] kaolinite clay mineral has the least affinity for water among the clay minerals will usually exhibit moderate shrinkage and swelling on drying and on wetting respectively. It is to mention that the type and quantity of clay minerals present in a soil can make a tremendous influence on the soil behavior when exposed to different environmental conditions [25]. Thus, an investigation method combining macro- and micro-analysis allows one to deeply understand the mechanical properties of clay soils [26]. The quantitative analysis of XRD in Table 3 revealed that the kaolinite clay mineral has the major portion of the laterite soil with $69.5 \%, 20.4 \%$ gibbsite, $6.5 \%$ cristobalite and $3.6 \%$ goethite.

Table 2. Oxide composition of laterite soil.

\begin{tabular}{|c|c|}
\hline Property & Value (\%) \\
\hline $\mathrm{SiO}_{2}$ & 25.46 \\
\hline $\mathrm{Al}_{2} \mathrm{O}_{3}$ & 31.10 \\
\hline $\mathrm{Fe}_{2} \mathrm{O}_{3}$ & 35.53 \\
\hline $\mathrm{CO}_{2}$ & 7.91 \\
\hline
\end{tabular}

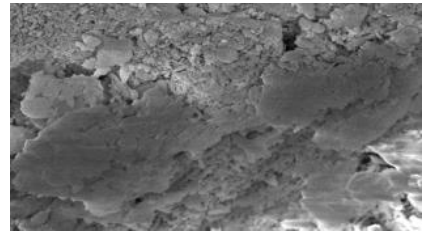

(a)

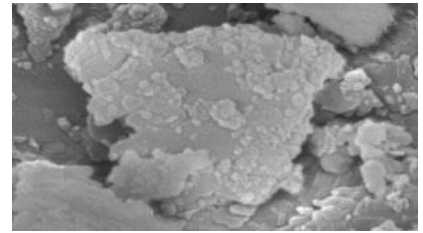

(b)

Fig. 4. (a) and (b) Showing Micrograph using FESEM at: 10,000 and 50,000 Magnification. 


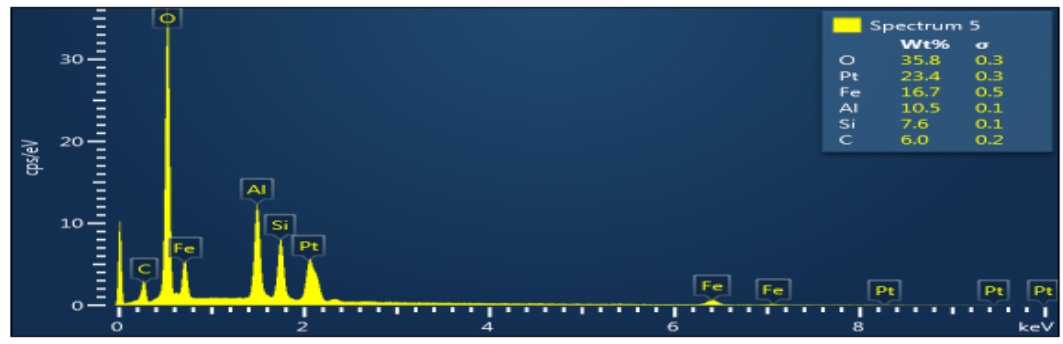

Fig. 5. EDX Spectrum.

Table 3. XRD quantitative analysis.

\begin{tabular}{|c|c|}
\hline Property & Value (\%) \\
\hline Kaolinite & 69.5 \\
\hline Gibbsite & 20.4 \\
\hline Goethite & 3.6 \\
\hline Cristobalite & 6.5 \\
\hline
\end{tabular}

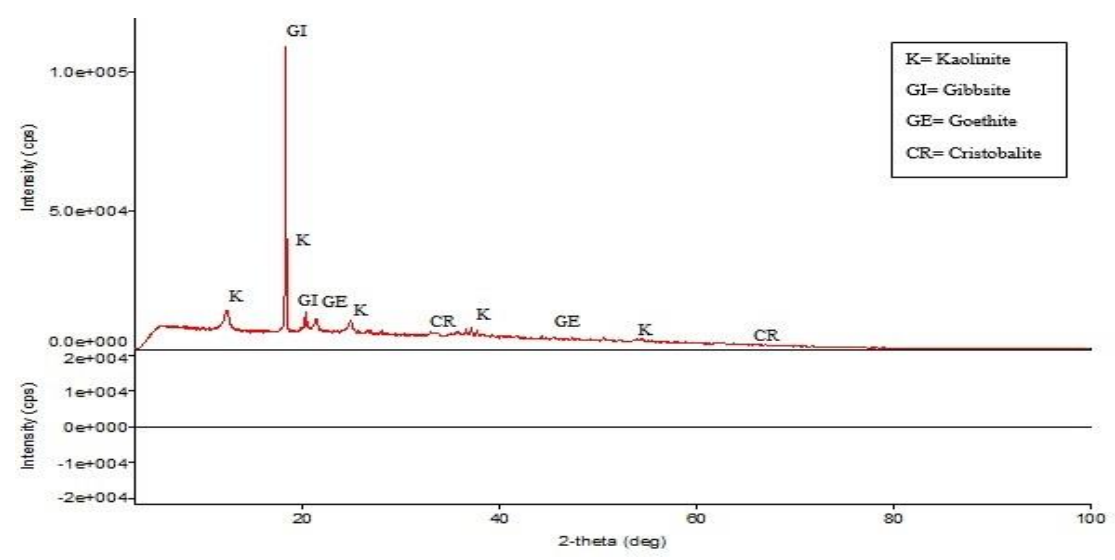

Fig. 6. XRD pattern.

\subsection{Hydraulic Conductivity}

The effect of fines content on low hydraulic conductivity is expected to be attained when the soil is well graded, and the clay fraction governs the hydraulic behaviour of the soil matrix [27]. The fines in a soil have a higher impermeabilizing effect if they are well distributed so they can most effectively plug voids among the larger particles. Mechanical mixing distributes fines and breaks down some of the soil aggregates thereby supplying fines for void-plugging and destroying large voids [28]. There is a general decrease in hydraulic conductivity with higher fines content as shown in Fig. 7. Hydraulic conductivity of $30 \%, 40 \%$ and $50 \%$ fines decreased to $2.5 \times 10^{-6}, 3.78 \times 10^{-8}$ and $2.44 \times 10^{-9} \mathrm{~m} / \mathrm{s}$ respectively on OMC. Similarly, hydraulic conductivity of $30 \%, 40 \%$ and $50 \%$ fines decrease to $1.55 \times 10^{-7}, 8.13 \times 10^{-9}$ and $1.02 \times 10^{-9} \mathrm{~m} / \mathrm{s}$ respectively on the wet sides of optimum. Unlike 
OMC and wet of OMC, hydraulic conductivity of $30 \%, 40 \%$ and $50 \%$ fines decrease to $9.87 \times 10^{-6}, 5.08 \times 10^{-8}$ and $9.1 \times 10^{-9} \mathrm{~m} / \mathrm{s}$ respectively on the dry side of OMC. The hydraulic conductivity differs with about one order of magnitude with respect to fines content. The maximum regulatory hydraulic conductivity value of $10^{-9} \mathrm{~m} / \mathrm{s}$ was attained at $50 \%$ fines content for the laterite soil investigated. More pronounced result at the $50 \%$ fines content is obtained on the wet side of OMC. This indicates that higher moulding moisture contents results to lower hydraulic conductivity.

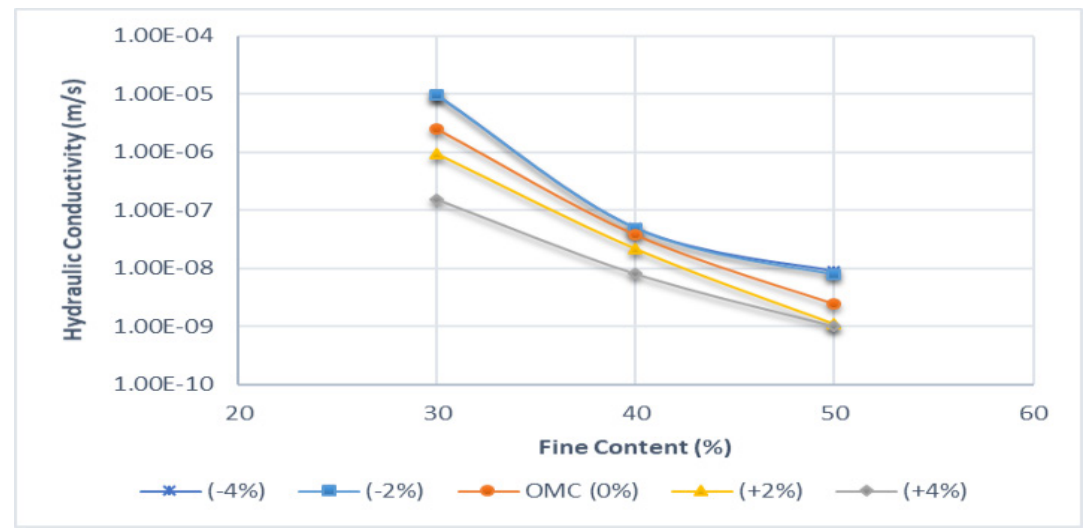

Fig. 7. Hydraulic Conductivity Versus Fines Content.

\section{Conclusions}

This research technically analyzed the effects of fines content and morphological features of laterite soil as liner in waste containment facilities. The spectroscopic and microscopic techniques revealed the laterite soil to contain kaolinite as the major predominant clay mineral. Hydraulic conductivity decreases with higher fines content. The permeability coefficient of the soil at $50 \%$ fines content gives the recommended value of $1 \times 10^{-9} \mathrm{~m} / \mathrm{s}$. Percentage of fines content lower than $50 \%$ did not meet the hydraulic conductivity requirement. The studied laterite soil is suitable for use as soil liner when contains up to $50 \%$ fines content.

The authors thankfully acknowledge the monetary supports provided by the Ministry of Education (MOE) through Universiti Teknologi Malaysia (UTM) under the Fundamental Research Grant Scheme (FRGS - VOT NO 4f885).

\section{References}

1. F. Akcanca and M. Aytekin, Env. earth sci 72, pp. 59-66 (2014)

2. A. Bello, The Pac. J. Sci. Tech 12, 425-434 (2011).

3. H. M. A. Rashid, J. Wanigarathna, L. Kurukulasuriya, N. Priyankara, A. Alagiyawanna, T. Saito, K. Kawamoto, Env. Earth Sci 76, 396 (2017).

4. Y. B. Yamusa, K. Ahmad, and N. A. Rahman, Malay. J. Civ. Eng. vol. 29, 153-164 (2017).

5. A. Bello, The Pac. J. Sci. Tech 16 (2015).

6. K. J. Osinubi and C. M. Nwaiwu, J. geotec. geoenv. eng, 132, 203-213 (2006). 
7. MHLG, Ministry of Housing and Local Government, Criteria for Siting Sanitary Landfills: National Strategic Plan for Solid Waste Management 3, Appendix 6B, Kuala Lumpur, Malaysia, (2005).

8. D. E. Daniel and Y.-K. Wu, J. Geotec. Eng 119, 223-237 (1993).

9. USEPA, Design and construction of RCRA/CERCLA final covers, Soils Used in Cover Systems, EPA/625/4-91/025. United States Environmental Protection Agency, 1-25 (1991).

10. UKEA. (2014). Earthworks in landfill engineering: LFE4.

11. D. E. Daniel, Geotechnical practice for waste disposal (Springer Science \& Business Media, 2012)

12. K. Osinubi, A. Eberemu, A. Bello, and A. Adzegah, Nig. J. of Tech 31, 277-287 (2012)

13. N. Latifi, A. S. A. Rashid, A. Marto, and M. M. Tahir, Env. Earth Sci 75, 1-9 (2016).

14. K. H. Head and R. J. Epps, Manual of soil laboratory testing 2, (Whittles publishing, Dunbeath, Caithness KW6 6EY, Scotland, UK., 2011)

15. BS1377, Methods of Testing Soil for Civil Engineering Purposes, (British Standards Institute, London, 1990)

16. C. H. Benson, H. Zhai, and X. Wang, J. Geotec. Eng, 120, 366-387 (1994)

17. N. Latifi, A. Marto, and A. Eisazadeh, Env. Earth Sci, 73, 1133-1141 (2015)

18. A. Marto, N. Latifi, and A. Eisazadeh, Arab J. Sci. Eng., 39, 6949-6958 (2014)

19. N. Latifi, A. S. A. Rashid, N. Ecemis, M. M. Tahir, and A. Marto, Arab J. Geosc, 9, 112 (2016)

20. K. S. Bawa, J. Soil Mec. F. Div, ASCE, 83, 1 - 15 (1957)

21. A. Eisazadeh, K. A. Kassim, and H. Nur, Eng. geo, 154, 36-41 (2013)

22. A. A. Bello, KSCE J. Civ. Eng, 17, 939-948 (2013)

23. X. Zhang, L. Kong, X. Cui, and S. Yin, Eng. Geo. Env, 75, 1493-1503 (2016)

24. I. Oyediran and C. Iroegbuchu, Ife J. Sci, 15, 17-30 (2013)

25. A. Eisazadeh and H. Eisazadeh, Env. Earth Sci, 74, 377-384 (2015)

26. Y. Zhao, Q. Xue, F.-x. Huang, X.-t. Hu, and J.-s. Li, Env. Earth Scie, 75, 1-9 (2016).

27. D. E. Daniel and C. H. Benson, J. Geotec. Eng, 116, 1811-1830 (1990)

28. C. H. Benson and J. M. Trast, Clay. clay min., vol. 43, pp. 669-681 (1995). 